\title{
All that glitters are not gold: holds true in female adnexal lesions
}

\author{
Mohamed Rafi Kathar Hussain, N. Kulasekeran, A. M. Anand and Rajasree Dhinadhyalan
}

\begin{abstract}
Background: Adnexal mass lesions are commonly encountered pathologies that creates diagnostic challenges for radiologist. Diffusion weighted imaging is a vital tool in the radiologist armamentarium for improving the diagnostic accuracy of adnexal lesions other than routine spine echo sequences.

Main body: Functional information about the lesion regarding the mobility of the water molecules in its tissue is assessed by diffusion weighted imaging. In addition to the solid malignant neoplasm, normal blood, fat, necrosis and pus also shows restricted diffusion.

Conclusion: All the lesion that shows restriction in the DWI are not malignant, but converse is mostly true. Knowledge regarding the non-malignant lesion in the ovary that shows restricted diffusion will give a clue in diagnosis, management and treatment of the adnexal lesions.
\end{abstract}

Keywords: DWI, Adnexa, Female, Ovary, Restricted diffusion

\section{Background}

Adnexal mass lesions are commonly encountered pathologies that creates diagnostic challenges for radiologist. The morphological analysis of lesion character by USG will help in most of the cases [1]. But MRI plays a significant role in differentiation by assessment of soft tissue characteristics. In addition to routine spin echo sequences, it is an indisputable fact that DWI provides a good characteristic of the lesion [2]. In general, all over the body; Diffusion restricted lesions are malignant. The main purpose of this review article is there are many exceptions to the above general statement. All DWI restricted lesion are not malignant, and all malignant lesion will not show diffusion restriction. DWI imaging is a vital tool in the radiologist's armamentarium, in improving the diagnostic accuracy of adnexal lesions and avoiding the pitfalls during interpretation [3].

*Correspondence: dhinadhayalan.rajasree@gmail.com Department of Radio Diagnosis, Sri Manukula Vinayagar Medical College, Kalitheerthalkuppam, Puducherry, India

\section{Basics of DWI}

The tissues in the body has water molecules that show constant and random motion, known as brownian movement, which is slowed down by interaction with the cell membranes and intracellular organelles. DWI gives the information about the brownian motion of the moving water molecules at cellular levels [4]. Increased cellularity in the tissues makes the surface area of cell membrane to increase, thus decreasing the brownian motion. ADC quantifies loss of signal in corresponding high signal areas of DWI,which is called as restricted diffusion. The b value predicts variable diffusion gradient strengths which is used to acquire the DWI image and it is expressed as s/ $\mathrm{mm}^{2}$ (time/area) [5].

\section{Pitfalls in DWI}

In addition to the malignant neoplasm which shows restricted diffusion; Hemorrhage, fat, necrotic areas and abscess may also shows restricted diffusion [6]. This leads to overlap in the radiological diagnosis which creates a diagnostic challenge with neoplastic lesion [7]. T2 WI also helps in assessment of DWI signal intensity. The tissues having increased $\mathrm{T} 2$ relaxation time will show high 
signal intensity in DWI and ADC is called T2-shinethrough effect. Some lesions cause hypointense signal on DWI, the ADC map, and T2W images. This is called as T2-blackout effect. This T2 blackout effect is seen in fibrous lesions and chronic hemorrhage. We will describe the lesions which are exception to the general rules of DWI as given in the Table 1.

Normal ovaries are oval in shape with average volume $\sim 10 \mathrm{~cm}^{3}$ normally [7]. On T2W images the zonal anatomy of ovary is best seen. The normal medulla with respect to cortex shows increased signal intensity. Usually the medulla has an increased amount of stroma which is loosely packed and blood vessels. Cortex which has thin walled follicles shows high signal in T2WI and low signal intensity on T1W images [7]. Contradictory to it, corpus luteum has thick wall, shows intermediate to low signal intensity on $\mathrm{T} 2 \mathrm{~W}$ images, which corresponds to a layer of theca cells [8]. Sometimes, the normal ovary may show increased signal intensity on DWI sequences, especially during the luteal phase due to T2-shine-through effect. The thin walled ovarian follicles, on all DWI sequences shows high signal intensity (even at high b values), with corresponding high ADC values [9].

\section{Mature cystic teratoma}

For women under 45 years of age, mature cystic teratoma is the most common ovarian tumors [10]. They are combination of endoderm, mesoderm and ectoderm or any of the two-germ cell layer. Most of the teratomas are unilateral except for $10 \%$ which are bilateral. They have a slow growth rate at an average growth of about $1.8 \mathrm{~mm}$ each year. Most of the mature cystic teratomas have sebum within, which at body temperature gets liquified. The lining of teratoma is keratinized squamous epithelium [11]. They have hair follicles, glands, muscle component, and other solid tissues. Rokitansky nodule, an eccentric nodular projection is seen projecting into the cystic lesion in most of the lesion. Since they have adipose content, they show both T1 and T2 high signal intensity which becomes hypointense on fat saturation. This specific characteristic is sufficient to diagnose it as ovarian teratoma [12].
It is suggested that keratin component displays an abnormal increased signal intensity on DWI in most mature cystic teratomas. Restriction of Brownian motionof the molecules inside the keratinous material leads to DWI high signal intensity and low ADCs. DWI can facilitate the diagnosis of mature benign cystic teratomas, which has small amount of fat that is not identified by other conventional sequences (Fig. 1a-d). Loss of the normal diffusion restriction in certain areas which are previously restricted shows raise the suspicion of malignancy in teratoma.

\section{Endometriomas}

Endometriomas are the ectopic endometrial tissue outside the endometrium. There tissues responds to hormonal stimulation leading to repeated hemorrhage during menstruation. Patient usually presents with recurrent cyclical abdominal pain. T2 shading is the classic feature of endometriomas which appear as linear dependent hypointense signal within the lesion. The degraded blood products, protein and iron deposition appear hyperintense on T1with corresponding hypointense signal on T2WI.

Due to the presence of blood and some hemosiderin, endometriosis shows lower signal on ADCs, high signal intensity on DWI with T1 shortening [13]. Benign endometrioma will shows restricted diffusion, but loss of the diffusion restriction on previously diagnosed benign lesion should raise the suspicion of malignant transformation. The most frequent malignant tumors associated are clear cell and endometrioid carcinomas. Along with change in diffusion pattern with presence of intermediate signal intensity on $\mathrm{T} 2 \mathrm{~W}$ images, thick septa, post- contrast enhancement in solid nodules and peritoneal metastases are features of malignant transformation [14]. Mapping DWI and ADC also plays an important role in differentiating between endometrioma and hemorrhagic cyst. ADCs shows low signal in endometriomas than in hemorrhagic cysts. This can help in differentiating between the two conditions. (Fig. 2a-f).

Table 1 MRI features of various adnexal lesions

\begin{tabular}{|c|c|c|c|c|c|}
\hline S. no & Lesion & $\mathrm{T1}$ & $\mathrm{T} 2$ & DWI & ADC \\
\hline 1 & Mature cystic Teratoma & Hyperintense & Heterogeneous, predominantly hyperintense & Hyperintense & Hypointense \\
\hline 2 & Endometrioma & Hyperintense & Hypointense to intermediate Signal & Hyperintense & Hypointense \\
\hline 3 & Ovarian Torsion & Hyperintense & Hyperintense & Hyperintense & Hypointense \\
\hline 4 & Tubo-ovarian abscess & Heterogenous & Heterogenous, predominantly hyperintense & Hyperintense & Hypointense \\
\hline 5 & Fibroma & Hypointense & Hypointense to Intermediate signal & Hypointense & Hypointense \\
\hline
\end{tabular}



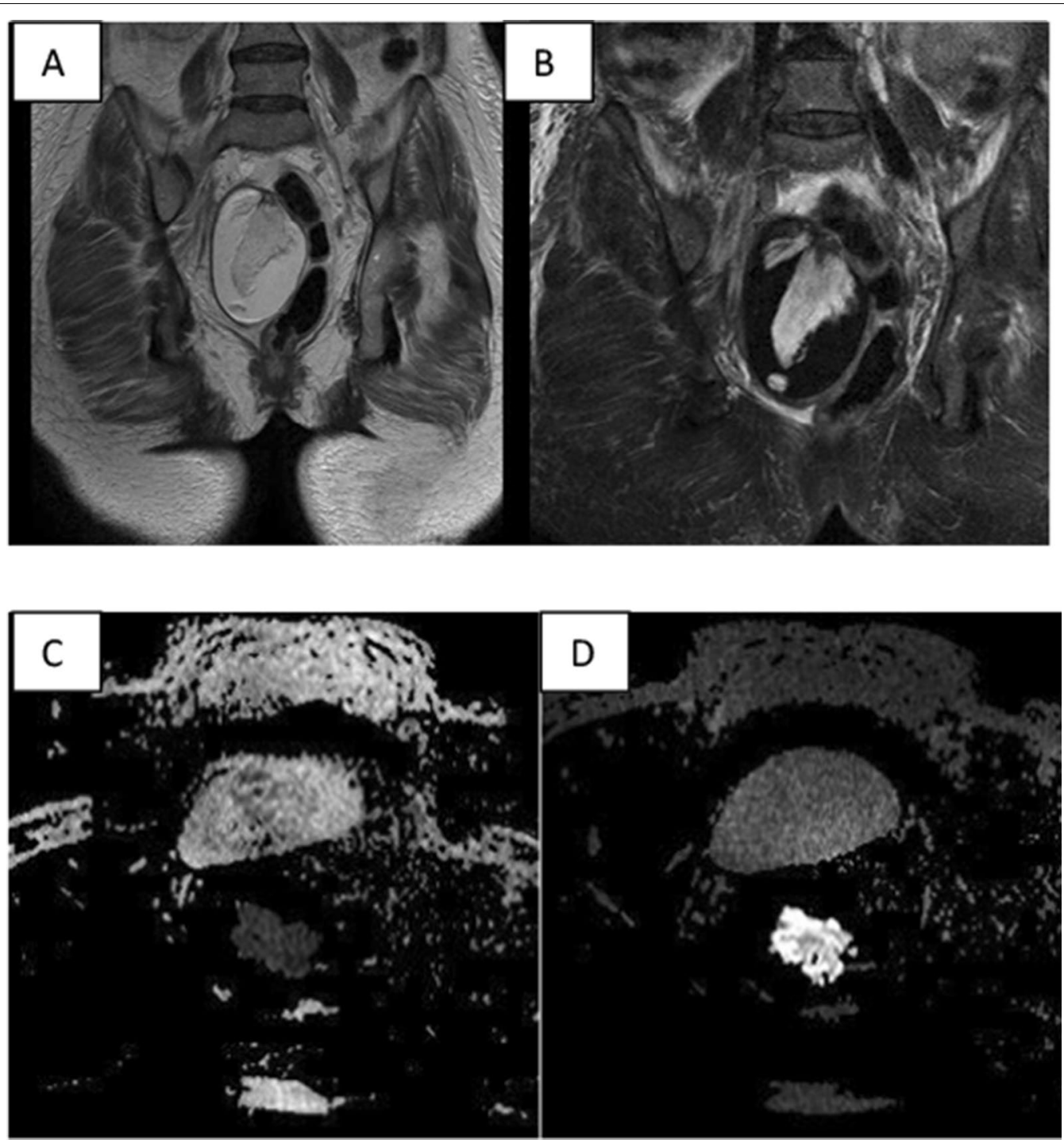

Fig. 1 Shows 38-year-old female with lower abdominal pain. a T2W MRI coronal image shows well defined hyperintense right ovarian lesion. b Fat saturation sequence shows suppression of fat within the lesion. $\mathbf{c}$, $\mathbf{d}$ shows DWI image axial section with areas of restricted diffusion and corresponding signal loss in ADC. MRI features suggestive of mature cystic teratoma. CT of the same patient shows presence of Fat, calcification and soft tissue elements in the right ovary

\section{Ovarian torsion}

Complete or partial rotation of the ovarian vascular pedicle which causes obstruction to vascular flow is defined as ovarian torsion. Adnexal torsion is unilateral more common on the right side with a 3:2 predilection. Benign tumors such as mature cystic teratoma, ovarian cyst are the common predisposing factors associated with torsion [15]. It occurs due to the twists of suspensory ligament. Suspensory ligament is the one that attaches the ovary to pelvic sidewalls. Initially torsion compromises the venous blood flow and lymphatic outflow. This will lead to ovarian edema and bulky ovary on imaging. Later, as torsion progresses there is compromise of arterial circulation leads to thrombosis, progressing to ischemia and ovarian infarction [16].

Immediate surgical intervention is essential [17]. If it is left untreated ovarian infarction will progress to infection, leading to peritonitis and can further lead to intestinal obstruction. If there is partial torsion it will lead to intermittent pain and relief on spontaneous untwisting within hours, days, or weeks [18]. Imaging features of partial torsion will vary depend upon which stage of torsion imaging was done. Early surgical detorsion can prevent salphingectomy and other complications. The 


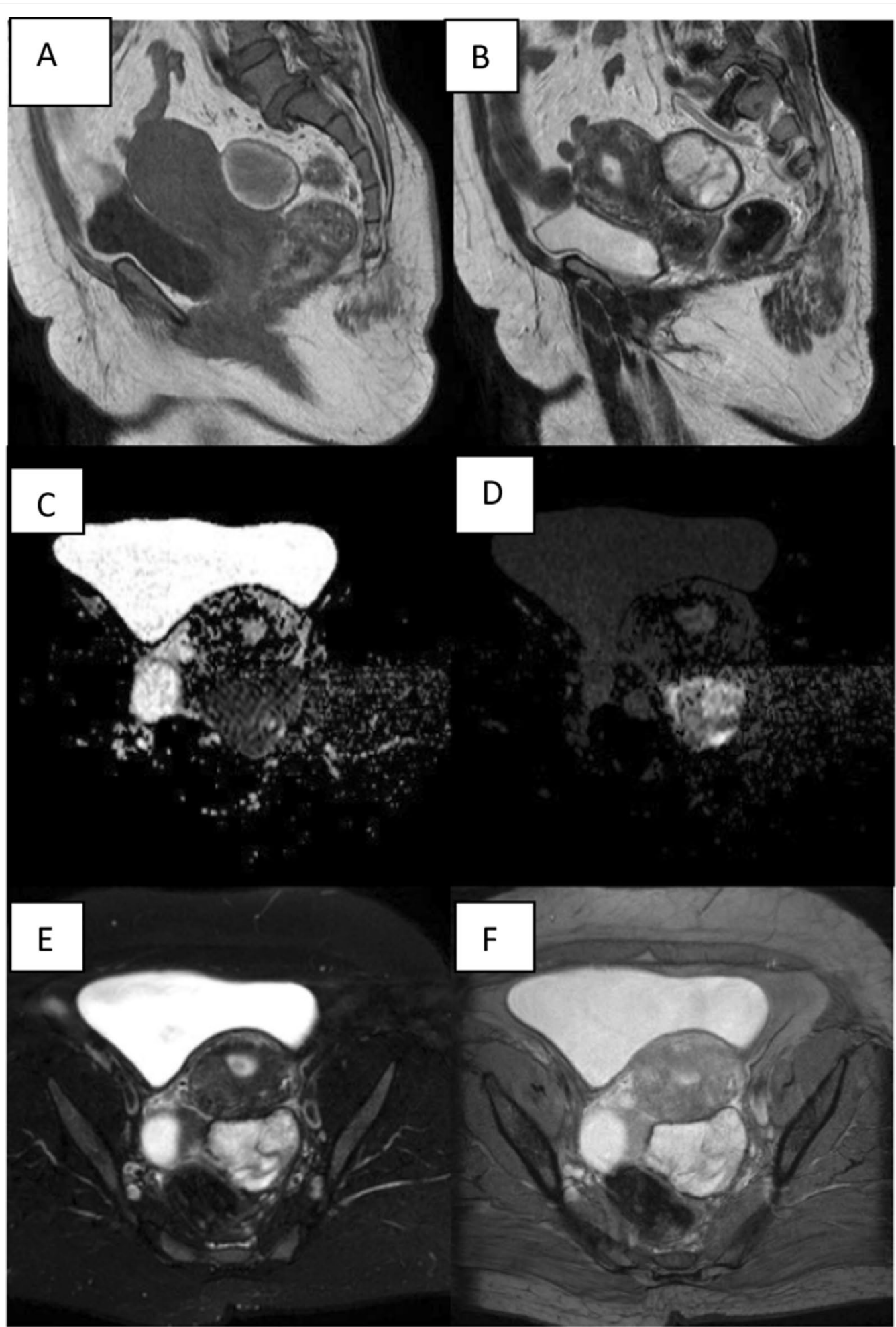

Fig. 2 A 40 year old female came with recurrent cyclical abdomen pain varying with menstrual cycle. a, b Sagittal T1 and T2W MRI shows well defined cystic lesion seen in the posterior fornix and torus uterinus. The lesion appears T1-Hypointensity and T2- Hyperintensity, probably originating from the left ovary. Left ovary not seen seperately. $\mathbf{c}, \mathbf{d}$ ADC and DWI axial image demonstrating few areas of T2 shadowing and the lesion shows Restricted diffusion, e T2 fat suppression axial section which appears hyperintense. No evidence of fat suppression. $\mathbf{f}$ on FFE sequence, complete hemosiderin rim seen.MR Imaging features suggestive of endometrioma arising from the left ovary, confirmed by surgery 
salvage rate is very low in adults (below 10\%) when compared to children $27 \%$ [19].

In ovary with torsion, the mean $\mathrm{ADC}$ valueis lower than that of ovary without torsion. And it is significantly lower in patients with hemorrhagic infarction [20]. Torsion leads to cytotoxic edema and causes diffusion restriction on DWI [21]. Meanwhile hemorrhage will have magnetic susceptibility effect on DWI which results in low ADC values [22, 23].

\section{Tubo-ovarian abscess}

Tubo-ovarian abscess may appear as a frank abscess or tubo-ovarian inflammatory mass, which results from breakdown of fallopian tubes and ovaries. TOA is most common in patients with Pelvic inflammatory disease. Use of an intrauterine device (IUD), like $\mathrm{Cu}-\mathrm{T}$ is associated with an increased incidence of TOA in young patients [24].

If the content of tubo-ovarian abscess becomes more viscious, it shows restricted diffusion in DWI with corresponding low signal on ADC map [25] (Fig. 3a-d). But in chronic abscesses or abscesses smaller than $1 \mathrm{~cm}$, if started on antibiotic therapy will not show restricted diffusion on DWI [26].

\section{Fibroma or thecoma}

Around 4\% of all ovarian neoplasm's accounts for fibromas [27]. Most commonly seen in 4th decade. They are classified into two types either cellular fibromas or fibrosarcoma's. Malignant potential is low in cellula fibromas, whereas fibrosarcoma's have a high malignant potentials [28]. On T1W and T2W MRI, fibromas usually show low intensity signal and delayed post- contrast enhancement. T2 shows a predominantly low signal intensity lesion which is due to increased collagen and the reduced extracellular fluid [29]. On T2W images, few areas of shows intermediate to high signal intensity due to edema and cystic degeneration [30].

Thecomas presents around $0.5-1.0 \%$ of all ovarian tumors and are more common in post- menopausal

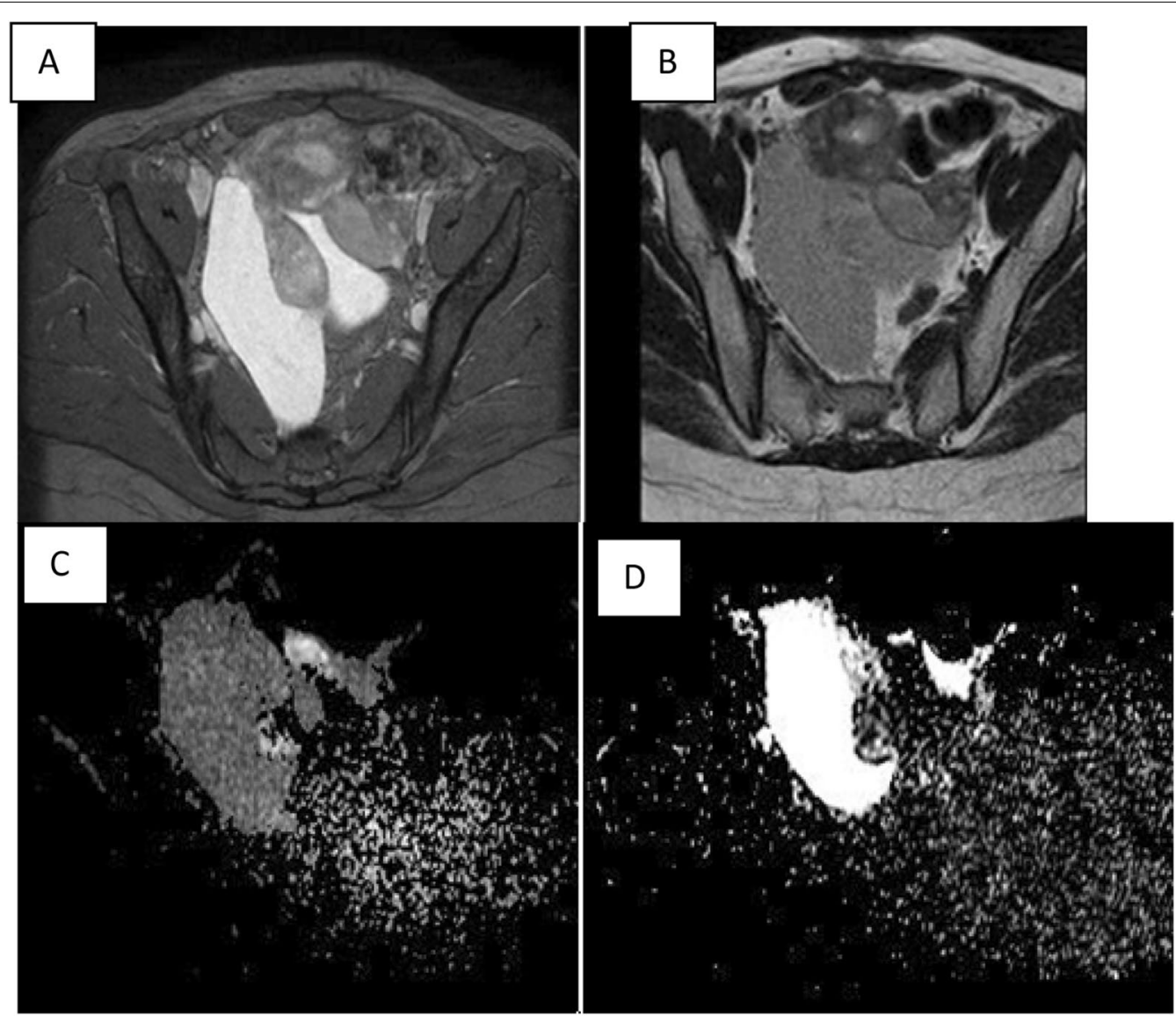

Fig. 3 A 30 year old female with fever, vaginal discharge and lower abdominal tenderness. a, b T2WI and T1WI axial section shows well defined solid and cystic lesion in the left adnexa, which appears T2 hyperintense and T1 hypointense. Adjacent mesosalpinx appears mildly thickened and inflammed. Surrounding pelvic fat planes shows mild enhancement. $\mathbf{c}$, $\mathbf{d}$ shows restricted diffusion on DWI images with corresponding signal loss in ADC. MRI features suggestive of Tubo-ovarian abscess. Patient also had a peritoneal inclusion cyst on right side 
women. They are considered as benign neoplasms [31]. They will estrogenic activity due to hormonal production. On MRI, on comparison with fibrous tumors, pure thecomas exhibits a higher signal intensity on T2W images and more avid post-contrast enhancement.

According to the European Society of Urogenital Radiology, recent guidelines for adnexal masses, a solid lesion that depicts a low signal intensity on T2W images and restricted diffusion in DWI with high b values is highly predictive of benignity [32]. Low value of ADCs in fibrous tumors is due to dense fibrous stromal proliferation. And it is called as T2 blackout effect (Fig. 4a-d). Few fibromas and thecomas rarely show restricted diffusion [33, 34].

\section{Conclusions}

DWI image plays an important role in the diagnosing the ovarian adnexal lesion. All the lesion that shows restriction in the DWI are not malignant, but converse is mostly true. Knowledge regarding the nonmalignant lesion in the ovary that shows restricted diffusion will give a clue in diagnosis, management and treatment of the ovarian lesion.

\section{Learning points}

1. Lesion that shows restriction in DWI are not always malignant.

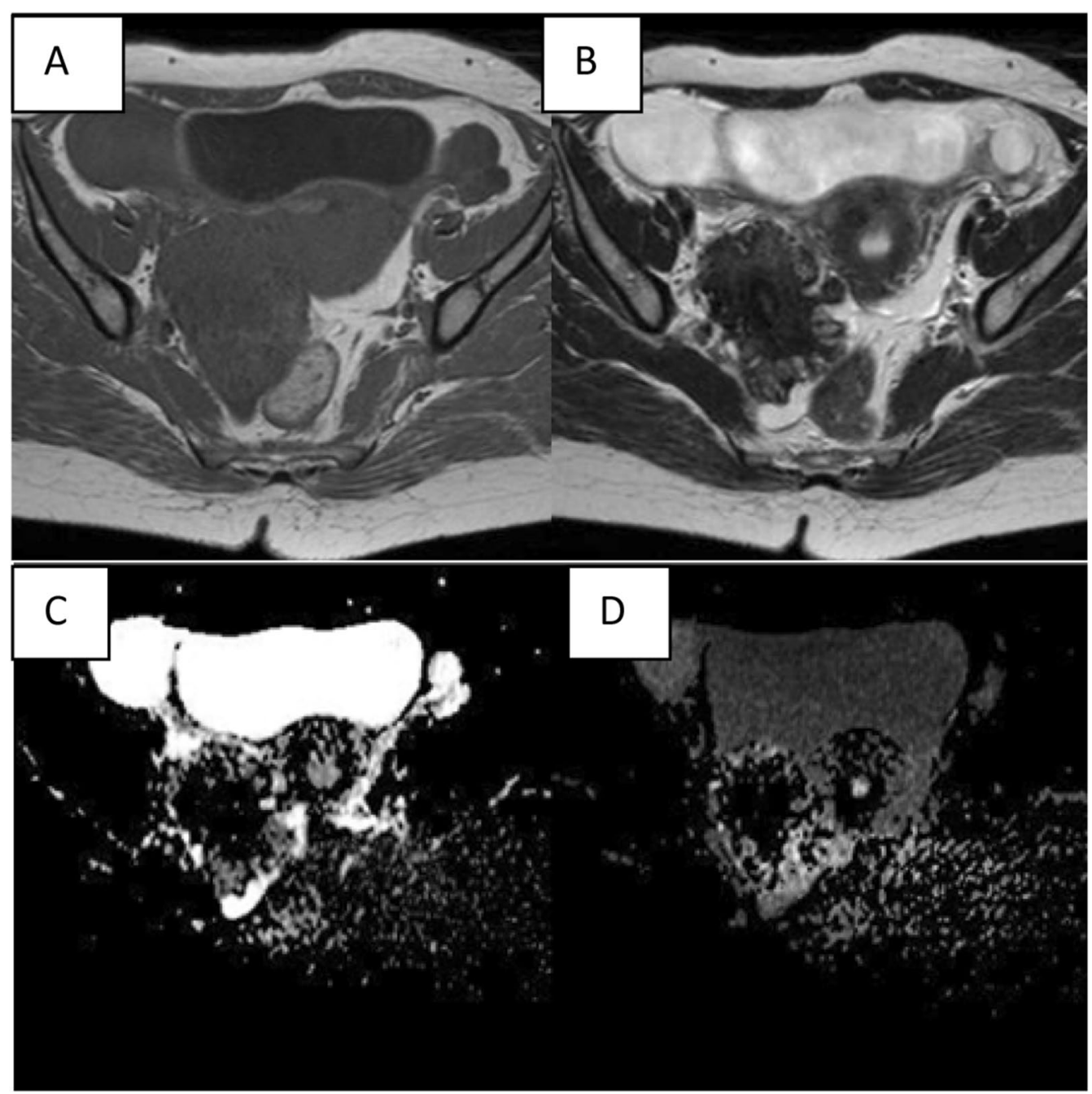

Fig. 4 A 40-year-old female came with irregular menstruation and lower abdominal pain. a, b MRI pelvis shows well defined T1 intermediate signal and T2 Hypointense mass with nodular surface in right adnexa. Low signal on T2WI depictsthe fibrous contents within the lesion, $\mathbf{c}, \mathbf{d}$ lesion appear Hypointense on both DWI and ADC images. On post contrast, lesion shows delayed mild heterogeneous enhancement. Lesion is confirmed as Fibrothecoma by histopathology 
2. Normal hemorrhage, lipid component, necrotic tissues and pus will also show restricted diffusion.

3. Benign fibrous ovarian lesion will not show restricted diffusion, there will be T2 blackening effect.

\section{Abbreviations}

USG: Ultrasonogram; MRI: Magnetic resonance imaging; DWI: Diffusion weighted imaging; ADC: Apparent diffusion coefficient; T2: T2 Weighted imaging sequence; T1: T1 Weighted imaging sequence; TOA:Tubo-ovarian abscess; PID: Pelvic inflammatory disease; IUD: Intra-uterine device.

\section{Acknowledgements}

None.

\section{Authors' contributions}

Dr MR KH (1st Author) collected the data, provided the image, concept for the article and provided the grammatical support in writing the paper. Dr KN (2nd Author) helped in supervising the paper, Dr AM (3rd Author) had provided the grammatical support in writing the paper. Dr RD (4th Author) wrote the complete manuscript. All authors read and approved the final manuscript.

\section{Funding}

None.

\section{Availability of data and materials}

Available.

\section{Declarations}

\section{Ethical approval and consent for participation}

Ethical approval is not obtained, since it's a retrospective study. Written consent had been obtained from the participant for participation.

\section{Consent for publication}

Written consent had been obtained from the patient for the publication.

\section{Competing interests}

The authors declare that they have no competing interests.

Received: 28 November 2020 Accepted: 8 August 2021

Published online: 16 August 2021

\section{References}

1. Jeong YY, Outwater EK, Kang HK (2000) Imaging evaluation of ovarian masses. Radiographics 20(5):1445-1470

2. Agostinho L, Horta M, Salvador JC, Cunha TM (2019) Benign ovarian lesions with restricted diffusion. Radiologiabrasileira 52(2):106-111

3. Dhanda S, Thakur M, Kerkar R, Jagmohan P (2014) Diffusion-weighted imaging of gynecologic tumors: diagnostic pearls and potential pitfalls. Radiographics 34(5):1393-1416

4. Le Bihan D, lima M (2015) Diffusion magnetic resonance imaging: what water tells us about biological tissues. PLOS Biol 13(7):e1002203

5. Taouli B, Beer AJ, Chenevert T, Collins D, Lehman C, Matos C, Padhani AR, Rosenkrantz AB, Shukla-Dave A, Sigmund E, Tanenbaum L (2016) Diffusion-weighted imaging outside the brain: consensus statement from an ISMRM-sponsored workshop. J Magn Reson Imaging 44(3):521-540

6. Fayad LM, Jacobs MA, Wang X, Carrino JA, Bluemke DA (2012) Musculoskeletal tumors: how to use anatomic, functional, and metabolic MR techniques. Radiology 265(2):340-356

7. Hauth EAM, Jaeger HJ, Libera H, Lange S, Forsting M (2006) Magnetic resonance imaging of the ovaries of healthy women: determination of normal values. Acta Radiol 47(9):986-992
8. Bonde AA, Korngold EK, Foster BR, Fung AW, Sohaey R, Pettersson DR, Guimaraes AR, Coakley FV (2016) Radiological appearances of corpus luteum cysts and their imaging mimics. AbdomRadiol (NY) 41(11):2270-2282

9. Morisawa N, Kido A, Koyama T, Okada T, Kataoka M, Umeoka S, Fujimoto K, Tamai K, Togashi K (2012) Changes of the normal ovary during menstrual cycle in reproductive age on the diffusion-weighted image. J Comput Assist Tomogr 36(3):319-322

10. Tamai K, Koyama T, Saga T, Kido A, Kataoka M, Umeoka S, Fujii S, Togashi K (2006) MR features of physiologic and benign conditions of the ovary. Eur Radiol 16(12):2700-2711

11. Outwater EK, Siegelman ES, Hunt JL (2001) Ovarian teratomas: tumor types and imaging characteristics. Radiographics 21(2):475-490

12. Foti PV, Attinà G, Spadola $S$, Caltabiano R, Farina R, Palmucci $S$, Zarbo G, Zarbo R, D'Arrigo M, Milone P, Ettorre GC (2016) MR imaging of ovarian masses: classification and differential diagnosis. Insights Imaging $7(1): 21-41$

13. Nakayama T, Yoshimitsu $K$, Irie $H$, Aibe $H$, Tajima T, Nishie A, Asayama $Y$, Matake K, Kakihara D, Matsuura S, Nakano H (2005) Diffusion-weighted echo-planar MR imaging and ADC mapping in the differential diagnosis of ovarian cystic masses: usefulness of detecting keratinoid substances in mature cystic teratomas. J Magn Reson Imaging 22(2):271-278

14. Wu TT, Coakley FV, Qayyum A, Yeh BM, Joe BN, Chen LM (2004) Magnetic resonance imaging of ovarian cancer arising in endometriomas. J Comput Assist Tomogr 28(6):836-838

15. Chang HC, Bhatt S, Dogra VS (2008) Pearls and pitfalls in diagnosis of ovarian torsion. Radiographics 28(5):1355-1368

16. Duigenan S, Oliva E, Lee SI (2012) Ovarian torsion: diagnostic features on CT and MRI with pathologic correlation. Am J Roentgenol 198(2):W122-W131

17. Rha SE, Byun JY, Jung SE, Jung JI, Choi BG, Kim BS, Kim H, Lee JM (2002) CT and MR imaging features of adnexal torsion. Radiographics 22(2):283-294

18. Kimura I, Togashi K, Kawakami S, Takakura K, Mori T, Konishi NJ (1994) Ovarian torsion: CT and MR imaging appearances. Radiology 190(2):337-341

19. Phillips GS, Parisi MT, Chew FS (2011) Imaging diagnosis of right lower quadrant pain in children. Am J Roentgenol 196(5):W527-W534

20. Özdemir O, Metin Y, Metin NO, Küpeli A (2017) Contribution of diffusion-weighted imaging to conventional MRI for detection of haemorrhagic infarction in ovary torsion. BMC Med Imaging 17(1):56

21 Kato H, Kanematsu M, Uchiyama M, Yano R, Furui T, Morishige KI (2014) Diffusion-weighted imaging of ovarian torsion: usefulness of apparent diffusion coefficient (ADC) values for the detection of hemorrhagic infarction. Magn Reson Med Sci 13:39-44

22. Khedr SA, Kassem HM, Hazzou AM, Awad E, Fouad MM (2013) MRI diffusion-weighted imaging in intracranial hemorrhage (ICH). Egypt J Radiol Nucl Med 44(3):625-634

23. Keigler G, Goldberg I, Eichel R, Gomori JM, Cohen JE, Leker RR (2014) Diffusion-weighted imaging at b1000 for identifying intracerebral hemorrhage: preliminary sensitivity, specificity, and inter-rater variability. J Stroke Cerebrovasc Dis 23(7):1934-1938

24. Kim SH, Kim SH, Yang DM, Kim KA (2004) Unusual causes of tuboovarian abscess: CT and MR imaging findings. Radiographics 24(6):1575-1589

25. Feuerlein S, Pauls S, Juchems MS, Stuber T, Hoffmann MH, Brambs HJ, Ernst AS (2009) Pitfalls in abdominal diffusion-weighted imaging: how predictive is restricted water diffusion for malignancy. Am J Roentgenol 193(4):1070-1076

26. Unal O, Koparan HI, Avcu S, Kalender AM, Kisli E (2011) The diagnostic value of diffusion-weighted magnetic resonance imaging in soft tissue abscesses. Eur J Radiol 77(3):490-494

27. Zaino R, Carinelli SG, Ellenson LH, Eng C, Katabuchi H, Konishi I, Lax S, et al (2014) Tumours of the uterine corpus: epithelial tumours and precursors. In: Carcangiu ML, Herrington CS, Young RH (eds) WHO classification of tumours of female reproductive organs, 6 th edn. World Health Organization, Kurman, RJ, pp 126-132

28. Horta M, Cunha TM (2015) Sex cord-stromal tumors of the ovary: a comprehensive review and update for radiologists. Diagn Interv Radiol 21(4):277 
29. Imaoka I, Wada A, Kaji Y, Hayashi T, Hayashi M, Matsuo M, Sugimura K (2006) Developing an MR imaging strategy for diagnosis of ovarian masses. Radiographics 26(5):1431-1448

30. Shinagare AB, Meylaerts LJ, Laury AR, Mortele KJ (2012) MRI features of ovarian fibroma and fibrothecoma with histopathologic correlation. Am J Roentgenol 198(3):W296-303

31. Meinhold-Heerlein I, Fotopoulou C, Harter P, Kurzeder C, Mustea A, Wimberger P, Hauptmann S, Sehouli J (2016) The new WHO classification of ovarian, fallopian tube, and primary peritoneal cancer and its clinical implications. Arch Gynecol Obstet 293(4):695-700

32 Spencer JA, Forstner R, Cunha TM, Kinkel K, ESUR Female Imaging Sub-Committee (2010) ESUR guidelines for MR imaging of the sonographically indeterminate adnexal mass: an algorithmic approach. Eur Radiol 20(1):25-35

33. Duarte AL, Dias JL, Cunha TM (2018) Pitfalls of diffusion-weighted imaging of the female pelvis. Radiol Bras 51(1):37-44.https://doi.org/10.1590/ 0100-3984.2016.0208

34. Horta M, Cunha TM (2017) Pitfalls in imaging of female pelvic masses. Curr Radiol Rep 5(10):53

\section{Publisher's Note}

Springer Nature remains neutral with regard to jurisdictional claims in published maps and institutional affiliations.

\section{Submit your manuscript to a SpringerOpen ${ }^{\circ}$ journal and benefit from:}

- Convenient online submission

- Rigorous peer review

- Open access: articles freely available online

- High visibility within the field

- Retaining the copyright to your article

Submit your next manuscript at springeropen.com 